\title{
Prevalence Study of Stress Throughout Pregnancy
}

\author{
Zehra Ashraf*, Nimra Waheed* \\ Faculty of Pharmacy, Jinnah University for Women, Karachi, Pakistan
}

\section{ABSTRACT}

Background: Stress in pregnancy refers to a particular type of stress-related with the interaction with people or any other cause like workload, society etc. Today, however, we are increasingly exposed to prolonged stress which gives rise to problems such as sleep problems, headache, fatigue, memory disturbances and so on.

Stress in pregnancy can have a major impact on the mother as well as the developing fetus. Various symptoms and issues faced by the mother can indirectly have an adverse effect on the baby's development.

Aim of Study: The purpose of this study is to understand and identify the effect of stress on women during pregnancy.

Method: The research performed included 100 women which give us a general overview of how women of our society whether of high or low socioeconomic status cope with their stress or even understand the term "STRESS" in the first place. This study was carried out in various hospitals (maternity wards) to get an insight into our research. Various aspects were identified in order to draw out clear conclusions.

Result and Discussion: $83 \%$ of women agreed on the fact of suffering from stress during pregnancy, with the other $16 \%$ replying "NO" and the remaining $1 \%$ had no clue.

Considering the relationship of Socioeconomic factors are mostly affecting in pregnancy which is agreed by $66 \%$ of the female population while $18 \%$ disagree with this factor.

Conclusion: Our overall approach throws light on understanding and detecting these aspects during pregnancy. To help provide better alternatives and have a stress-free pregnancy.

\section{Keywords \\ Pregnancy, problems, behavior, health, stress.}

Cite this article: Ashraf Z, Waheed N. Prevalence Study of Stress Throughout Pregnancy. RADS

J. Biol. Res. Appl. Sci. 2019; 10(1): 18-22.

This is an Open Access article distributed under the terms of the Creative Commons Attribution License (http://creativecommons.org/licenses/by/4.0), which permits unrestricted use, distribution, and reproduction in any medium, provided the original work is properly cited.

\section{INTRODUCTION}

Stress is a feeling of strain and pressure. Small amounts of stress may be desired, beneficial, and even healthy ${ }^{1-3}$. Stress in pregnancy is defined as the imbalance that a pregnant woman feels when she cannot cope with demands which are expressed both behaviorally and physiologically ${ }^{4-6}$. Stress is the result of a cognitive appraisal (your mental interpretation) of what is at stake and what can be done about it ${ }^{-9}$. Stress during pregnancy is associated with multiple complications like insomnia anorexia etc. however interventions to prevent stress during pregnancy have been almost evaluated but up to some extent ${ }^{10-12}$. The importance of conducting such research helps us to better understand the possible outcomes on the health of the mother as well as the baby and to minimize the adverse effects caused by such forms of stress. It is essential to understand the sensitivity of the matter, each woman experiences and reacts differently to the kind of situation they are encountered with which further leads to the development of sometimes known and otherwise unconscious stress.

We sought to identify the factors associated with stress and to find new interventions to prevent and overcome such problems during the course of pregnancy. Our goal to conduct such research on this topic was for the 
betterment for our women and to spread awareness and highlight the problems which can be resolved within our society, to be able to acknowledge why being stress free during pregnancy can have an astonishing impact not only for the mother and the baby but for all the members directly or indirectly related to them.

\section{METHODOLOGY}

\section{Place of Study}

Karachi is one of the largest cities in the world. It is known as cities of lights and also the $2^{\text {nd }}$ largest populous city of the world, a cosmopolitan city of Pakistan.

\section{Propose of Study}

Cross-sectional analyses of data were conducted into various hospitals, parental care of Karachi from the $1^{\text {st }}$ of October to $31^{\text {st }}$ of December 2016.

The questionnaire was M.C.Qs based asking the women about how they are experiencing stress during pregnancy. We also provide some awareness to these women who didn't even aware of suffering from stress and diseases that cause by psycho-social stress. We also asked about their lifestyles that how it is affecting their health and what type of symptoms they observed other than pregnancyrelated complications. We collected the data after the survey and discussed our findings in this article which is represented by graphs for better understanding.

\section{RESULT}

Upon calibrating the results from our survey we concluded that about $83 \%$ of women were aware of the term STRESS whereas the other $16 \%$ don't know, shown in Figure 1.

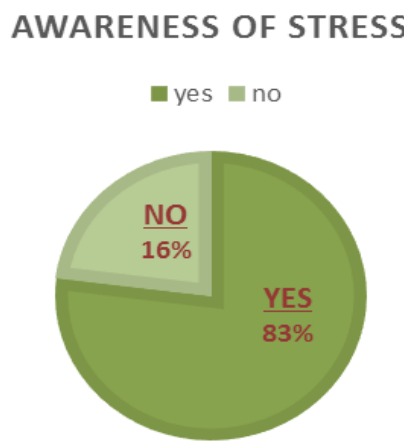

Figure 1. Aware with the term "STRESS" in pregnancy.
Further questions about whether they experienced stress during pregnancy lead to the observation that $77 \%$ suffered through stress whereas $23 \%$ of women were stress-free, presented in Figure 2.

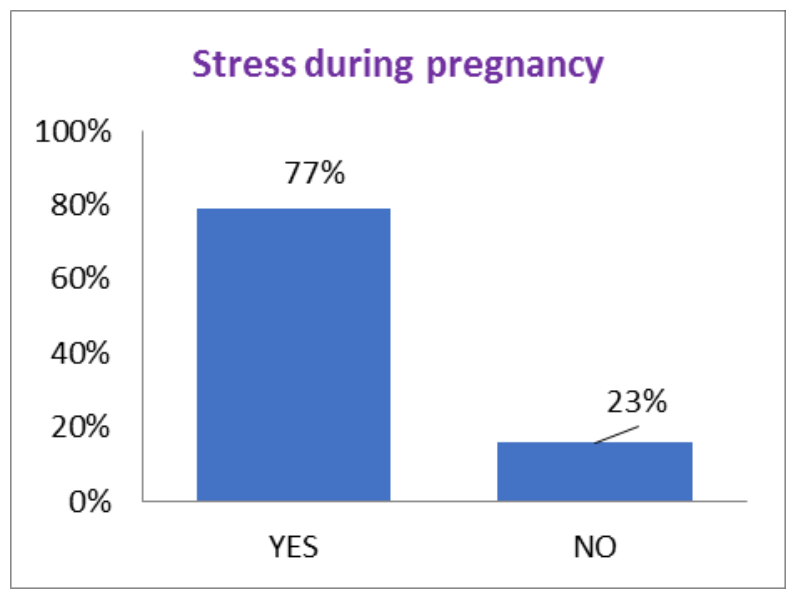

Figure 2. Illustrates the proportion of women facing various forms of stress during their pregnancy.

Moreover, we emphasized on the varied sorts of stresses in which $41 \%$ female experience pregnancy-related stress, $26 \%$ are dealing with discomfort, $14 \%$ occurrence of stress due to negative life experience, $8 \%$ of the women are scared of gender discrimination issues, $2 \%$ have long-lasting stress throughout the pregnancy while $9 \%$ occurrence of stress due to other issues (Figure 3 ).

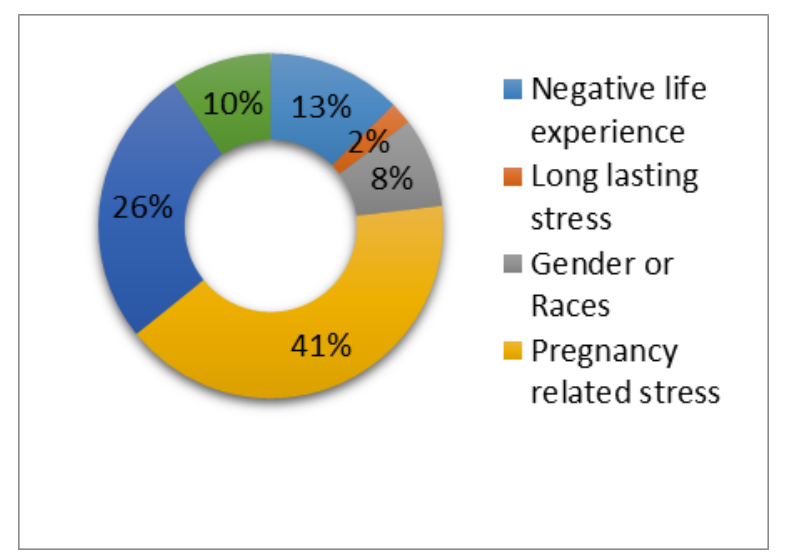

Figure 3. Points out to the varied sorts of stress that women face.

Figure 4 represents the $21.5 \%$ of women who preferred to take some sort of medication while $78.5 \%$ of female does not prefer to take any medication to relieve their stress. 


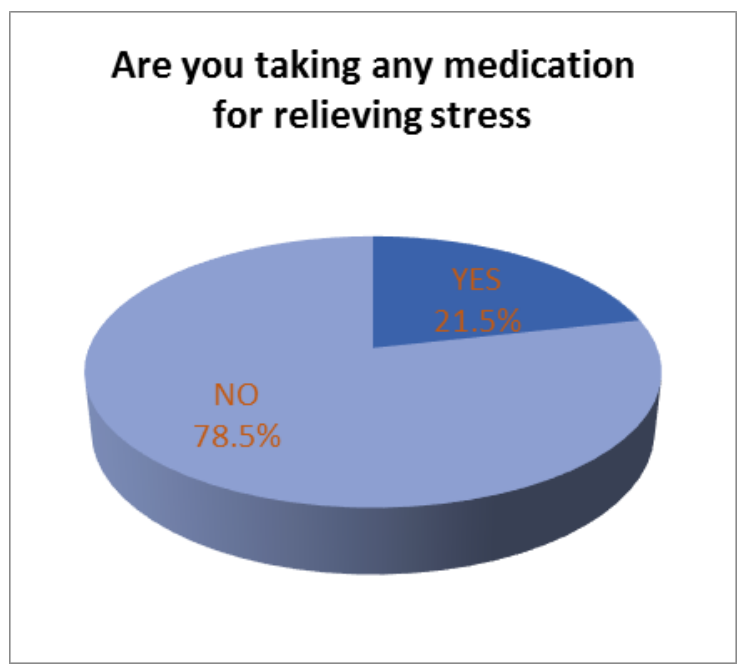

Figure 4. Taking medications for relieving stress during pregnancy.

Most of the vivid dreams occur in $3^{\text {rd }}$ trimester that is $23.7 \%$ while $11.8 \%$ in the $2^{\text {nd }}$ trimester and $8.6 \%$ in the $1^{\text {st }}$ trimester and $55.6 \%$ of the women does not have any vivid dream in whole pregnancy period (Figure 5).

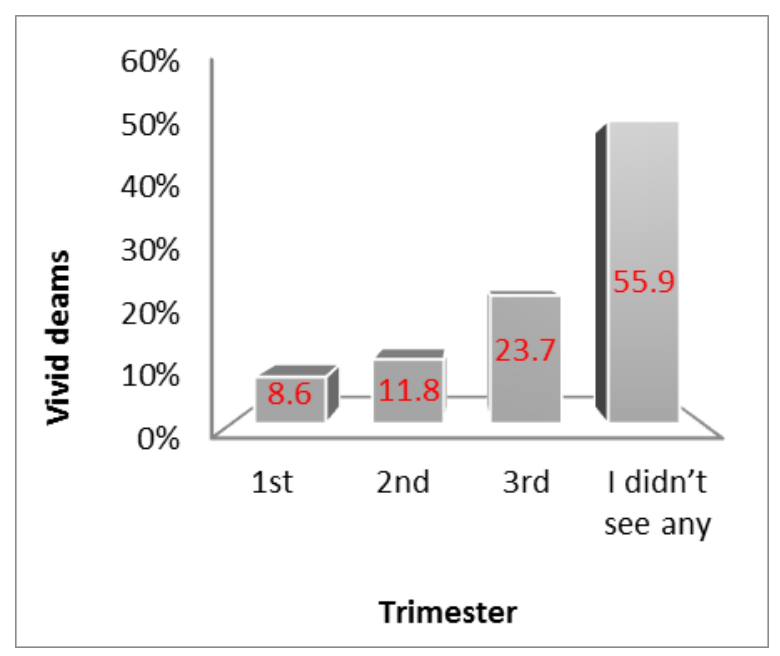

Figure 5. Occurrence of vivid dreams in pregnancy.

Socioeconomic factors are mostly affecting in pregnancy which is agreed by $66 \%$ of female population while $18 \%$ disagree this factor that is shown in Figure 6. $46.2 \%$ of housewife faced psychosocial stress during pregnancy while a higher rate of stress that is $53.7 \%$ was experienced by working women, this is illustrated in Figure 7.

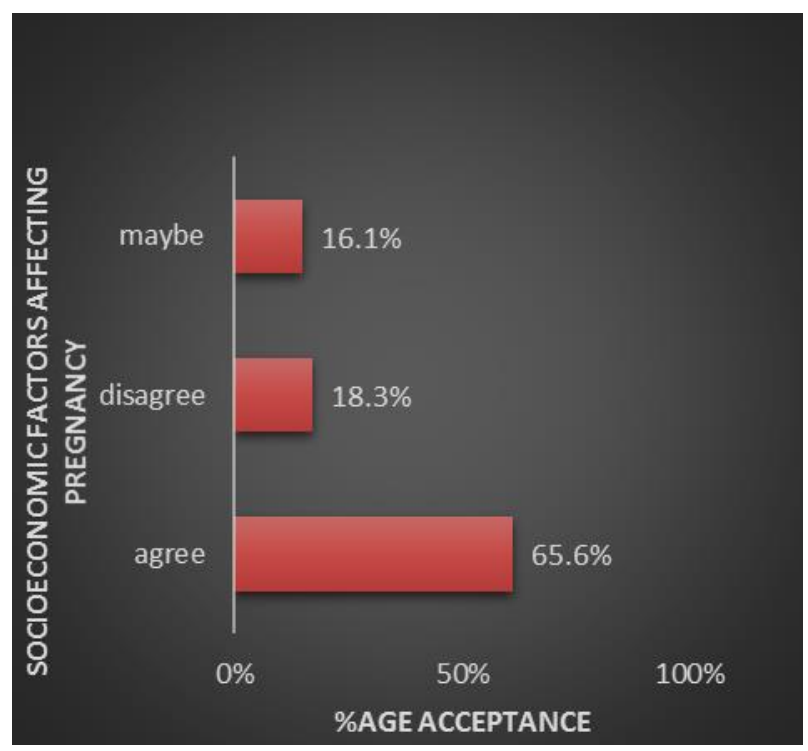

Figure 6. Socioeconomic factors affecting on pregnancy.

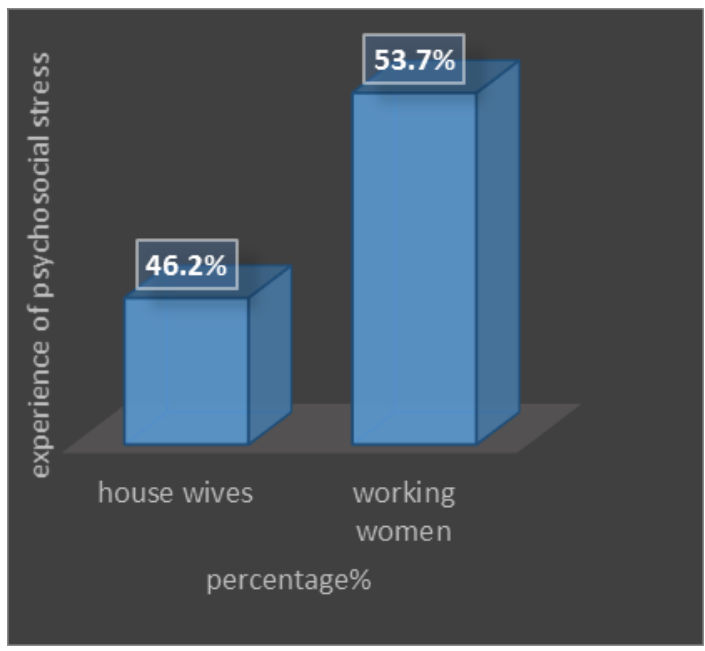

Figure 7. Percentage of women who agree upon the fact that working women experience more psychosocial stress than women who are home makers.

Many women experience a lot of symptoms which are $22.6 \%$ insomnia, $21.5 \%$ vomiting, $18.3 \%$ anxiety, $13.9 \%$ nausea, 7.5 headache, and $16.1 \%$ are other symptoms during pregnancy, presented in Table 1. Alternative ways of stress relief during pregnancy are represented in Table 2. $41.9 \%$ think that their stress can be reduced by talking with friends or other partners and $9.7 \%$ of women believed that exercise and healthy food can reduce their stress.

Physiological changes that have been observed during pregnancy are preeclampsia (6\%), Diabetes $(9 \%)$, edema (39\%) and others (28\%), these are shown in Table 3. 
Table 1. Symptoms of stress during pregnancy.

\begin{tabular}{cc}
\hline Symptoms of Stress & Percentage \% \\
\hline Anxiety & $18.3 \%$ \\
\hline Nausea & $13.9 \%$ \\
\hline Vomiting & $21.5 \%$ \\
\hline Insomnia & $22.6 \%$ \\
\hline Headache & $7.5 \%$ \\
\hline Others & $16.1 \%$ \\
\hline
\end{tabular}

Table 2. Demonstrates the various other ways women prefer to relieve their stress rather than choosing to take medicines.

\begin{tabular}{lc}
\hline $\begin{array}{l}\text { How do you cope up with your } \\
\text { stress usually, if you are not taking } \\
\text { medication }\end{array}$ & Percentage \% \\
\hline 1: Eating healthy food & 9.7 \\
\hline 2: Having plenty of sleep & 20.4 \\
\hline 3: Exercise (yoga or massage) & 9.7 \\
\hline 4: Talk to someone (friend or partner) & 41.9 \\
\hline 5: If other & 9.7 \\
\hline
\end{tabular}

Table 3. Physiological changes observed during pregnancy.

\begin{tabular}{cc}
\hline $\begin{array}{c}\text { Type of Physiological } \\
\text { Changes Observed During } \\
\text { Pregnancy }\end{array}$ & $\begin{array}{c}\text { Percentage of These } \\
\text { Changes Observed }\end{array}$ \\
\hline Preeclampsia & $6 \%$ \\
\hline Diabetes & $9 \%$ \\
\hline Edema & $39 \%$ \\
\hline $\begin{array}{c}\text { Others (obesity, stomach } \\
\text { problems, severe pain, etc.) }\end{array}$ & $28 \%$ \\
\hline
\end{tabular}

\section{DISCUSSION}

The survey was aimed to study stress in women that lead to specific pregnancy outcomes. The survey shows that $83 \%$ of women aware of the term STRESS, while $77 \%$ of women felt stress during pregnancy which includes different sort of stress. Most of the women took medications to cope with stress while some relay on diet and some took enough of sleep. The survey also elaborates that working women experience more stress than housewives, and the most common symptom due stress was vomiting and insomnia and occurrence of vivid dream especially in the $3^{\text {rd }}$ trimester. The stress leads to certain physiological changes in the body like preeclampsia, edema. While considering the relationship between socioeconomic status and stress it was found that $61 \%$ of women felt stress during pregnancy. (But this study is still in progress for the treatment of stress).

\section{CONCLUSION}

Evaluating the results from this study it can be concluded that women of our society face various forms of stress which can indirectly be the reason/cause of complication during pregnancy and may also have adverse effects on the fetus during/even after birth.

According to our study stress-free pregnancy is not possible because $83 \%$ women face stress whereas the remaining $16 \%$ have no idea about stress but they have a responsibility to other questions of which they experience during their pregnancies. This depicts that they were facing stress while the remaining $1 \%$ didn't experience stress during their pregnancies which is very less ratio comparatively to others.

Stress can be controlled by following alternative ways such as eating healthy foods, taking enough sleep, exercise like yoga and massage, talk to someone close to them etc. if stress is migrated it can cause harmful effects like preeclampsia, diabetes, edema, obesity severe pain etc. To avoid such situations proper guidance and counseling sessions must be provided to the conceived mother for better physical and mental wellbeing essential for both the mother and her child.

\section{REFERENCES}

1. Woods SM, Melville JL, Guo Y, Fan MY, Gavin A. Psychosocial stress during pregnancy. American journal of obstetrics and gynecology. 2010;202(1):61e1.

2. Ruiz R, Fullerton J. The measurement of stress in pregnancy. Nursing \& health sciences. 1999; 1(1):1925. 
3. Halbreich U. Prevalence of mood symptoms and depressions during pregnancy: implications for clinical practice and research. CNS Spectrums. 2004; 9(03):177-84.

4. Curry MA. The interrelationships between abuse, substance use, and stress during pregnancy. Journal of Obstetric, Gynecologic, \& Neonatal Nursing. 1998; 27(6):692-9.

5. Nuckolls KB, Cassel J, Kaplan BH. Psychosocial assets, life crisis and the prognosis of pregnancy. American journal of Epidemiology. 1972;95(5):43141.

6. Hobfoll SE. Conservation of resources: A new attempt at conceptualizing stress. American psychologist. 1989; 44(3):513.

7. Côté-Arsenault D. Threat appraisal, coping, and emotions across pregnancy subsequent to perinatal loss. Nursing research. 2007; 56(2):108-16.

8. Colman AD. Psychological state during the first pregnancy. American Journal of Orthopsychiatry. 1969; 39(5):788.
9. Alder J, Fink $\mathrm{N}$, Urech $\mathrm{C}$, Hösli I, Bitzer J. Identification of antenatal depression in obstetric care. Archives of gynecology and obstetrics. 2011;284(6):1403-9.

10. Okun ML, Roberts JM, Marsland AL, Hall M. How disturbed sleep may be a risk factor for adverse pregnancy outcomes a hypothesis. Obstetrical \& gynecological survey. 2009;64(4):273.

11. Sangsawang B, Sangsawang N. Stress urinary incontinence in pregnant women: a review of prevalence, pathophysiology, and treatment. International urogynecology journal. 2013; 24(6):90112.

12. Lupien SJ, McEwen BS, Gunnar MR. Effects of stress throughout the lifespan on the brain, and cognition. Nature reviews neuroscience. 2009; 10(6):434. 